\title{
Algorithm For Supporting Management Decision-Making On The Placement Of The Positions Of The Trunk Operators When Extinguishing Fires In The Tanks Of Vietnam
}

\author{
${ }^{1}$ Denisov A.N., ${ }^{2}$ Nguyen The Tai \\ ${ }^{1}$ Doctor of Technical Sciences Professor of the Academy of State Fire Service of the Ministry of Emergency \\ Situations of Russia, dan_aleks@ mail.ru \\ ${ }^{2}$ State Fire Service Academy EMERCOM of Russia, thetai.t34.36@ gmail.com
}

Article History: Received: 11 January 2021; Accepted: 27 February 2021; Published online: 5 April 2021

\begin{abstract}
In the article, based on the analysis of data in open literature sources, it was concluded that in the USSR, in the period 1950-1990, there were at least 10 tank fires per year, in the world - 8, 2000-2020 in Russia at least 5 fires in year, in Vietnam 1950-1990 - not less than 0,85 fires per year. And it is noted that since 2007, there have been no fires at the facilities of the oil refining complex in Vietnam. An algorithm is presented that allows you to select options for the location of personnel positions, for supplying a fire extinguishing agent for extinguishing a fire (by mixing) in tanks (in the absence of a roof) and for cooling the walls of burning and adjacent to the burning tanks. Using this algorithm, an analysis was carried out of the possible locations of the positions of the barrels in the tank farms of the Vietnamese oil refineries "Dung Quat" and "Ngi Son" for extinguishing and cooling the tanks during their burning.
\end{abstract}

Keywords: Algorithm, stirring method, cooling, placement, reservoir, quenching.

\section{Introduction}

It is traditionally believed that the fuel and energy complex, which is a system of interacting industries, is important for the successful development of the state. When analyzing and forecasting the development of the state, a wide range of factors is taken into account, this article pays attention to the issues of ensuring fire safety of the fuel and energy complex of Vietnam, included in the rank of priority - the objects of the oil refining complex.

Large fires at the facilities of the oil refining complex occur quite rarely 10 per year (according to open sources). Organizations (of the oil refining complex and not only), as a rule, mi nimize the publicity about fires, due to the fact that this can lead to a decrease in the financial quotations of companies on the stock exchanges, create conditions for social tension (Table 1). At the same time, fires demonstrate problems in the field of fire extinguishing management, management of organizations (oil refining complex), environmental protection.

Table 1. - The number of recorded tank fires by decades

\begin{tabular}{|l|l|l|l|l|l|l|l|}
\hline Decade & $1950 \mathrm{~s}$ & $1960 \mathrm{~s}$ & $1970 \mathrm{~s}$ & $1980 \mathrm{~s}$ & $1990 \mathrm{~s}$ & $2000 \mathrm{~s}$ & $2010 \mathrm{~s}$ \\
\hline $\begin{array}{l}\text { Number of fires in the world } \\
\text { (USA, Europe and several } \\
\text { English-speaking countries) }\end{array}$ & 13 & 28 & 80 & 135 & 161 & 92 & 69 \\
\hline $\begin{array}{l}\text { Number of fires in Russia } \\
\text { (USSR) }\end{array}$ & 80 & 150 & 98 & 86 & 67 & 20 & 86 \\
\hline Number of fires in Vietnam & 7 & 13 & 11 & 3 & 2 & 1 & 0 \\
\hline
\end{tabular}

Analysis of the data in the table and open literature sources [1-8] allows us to conclude that in the USSR, in the period 1950-1990, there were at least 10 fires per year, in the world - 8, 2000-2020 in Russia - at least 5 fires a year in Vietnam 1950-1990 - not less than 0,85 fires per year.

In Vietnam for "53 years from 1964 to 2020, 37 fires occurred in tanks with oil products. Including, for the period 1964 - 1975, there were 19 fires that arose as a result of the destruction of tanks from bombing and shells of American troops" [7, 8-]. Since 2007, there have been no fires at the facilities of the oil refining complex in Vietnam.

When accounting for fires in tank farms, the fact of a fire itself is taken into account, and not the number of burning tanks. Therefore, the number of fires was actually higher. When extinguishing fires, foam was almost always used; it was supplied both by stationary devices and mobile ones. The time of extinguishing a fire in tanks is influenced by the quantity, quality and performance of fire-fighting equipment, the logistics of focusing on fire extinguishing agents, substances and personnel, as well as the choice of tactics of warfare when extinguishing fires in a tank.

One of the factors affecting the management of fire departments when extinguishing fires in tanks is embankment - an area fenced off by a terrain or an artificial barrier capable of holding a layer of flammable liquid and a depth specified in regulatory and administrative documents. Due to the fact that the bunded area is also located in the open air, the weather conditions (wind, rain, temperature) affect the effectiveness of hostilities and they must be compensated. If the bunded area is cluttered with structures that can reduce the effectiveness of 
Algorithm For Supporting Management Decision-Making On The Placement Of The Positions Of The Trunk Operators When Extinguishing Fires In The Tanks Of Vietnam

hostilities, then this may require the use of additional forces and fire extinguishing equipment and a change in tactics.

Algorithmization of the choice of rational options for the placement of personnel positions when extinguishing fires in tanks by the mixing method

Taking into account the specifics of solving management problems and making decisions on extinguishing fires in tanks, an algorithm (Figure 1) has been developed to support management decisions on the placement of positions of fire brigade personnel and emergency rescue services, taking into account the trajectory of the jet from the fire barrel, which is exposed to the environment:

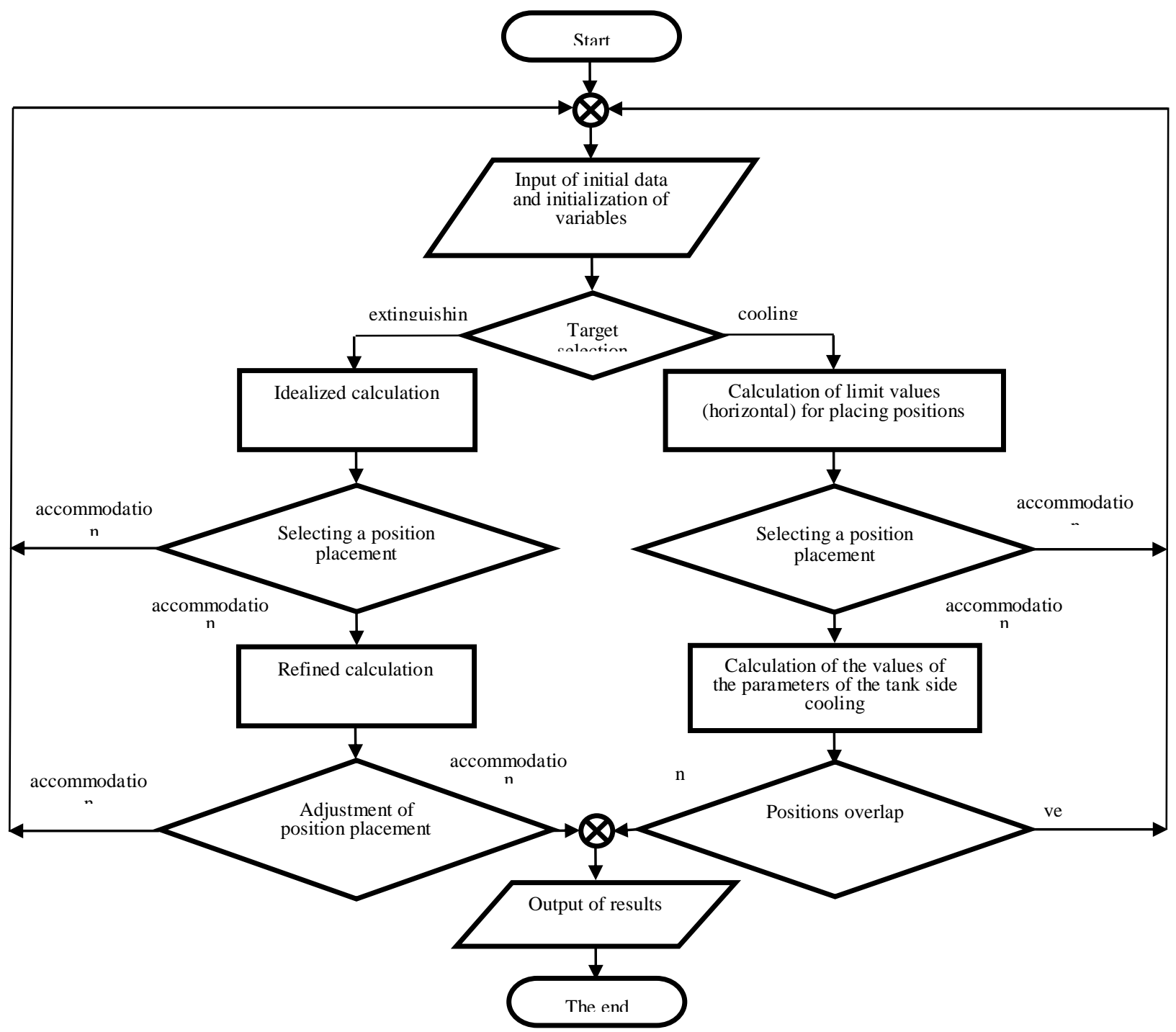

Figure 1. Block diagram of an algorithm for supporting the adoption of managerial decisions on the placement of positions of personnel of the fire protection and rescue services, taking into account the trajectory of the jet from the fire barrel, which is influenced by the environment

Ax1.1. Initialization of variables. Initialization of arrays: typical tanks, jet resistances, typical fire trucks, typical fire barrels.

Ax1.2. Entering and correcting the initial data for the calculation. $H$ - is the pressure at the fire barrel spray, m.w.st.; $x_{1}$ - distance from the position of the owner to the tank wall, $m ; y_{1}$ - tank side height, $m ; \alpha$-coefficient of resistance to jet movement;

Ax1.3. Condition (selection of the purpose of the calculation). Choice of quenching (stirring) or cooling. If extinguishing (stirring) is selected, then further. If cooling, then go to Ax1.8.

Ax1.4. Idealized calculation (determination of the angle of inclination of the axis of the fire barrel to the horizon $\left(\theta_{0}\right)$ so that the idealized trajectory of the water jet $\left(y(x)=x \cdot \operatorname{tg} \theta_{0}-\frac{x^{2}}{2 H} \cdot\left(1+\operatorname{tg}^{2} \theta_{0}\right)\right)$ passes through a certain point $\left(x_{1}, y_{1}\right)$. 
Ax1.4.1. We calculate $\operatorname{tg} \theta_{1,2}=\frac{2 H}{x_{1}} \pm \sqrt{\frac{4 H^{2}}{x_{1}^{2}}-\frac{4 H_{1}}{x_{1}^{2}}-1}$

Ax1.4.2. We calculate two angles of inclination of the axis of the fire barrel to the horizon $\theta_{0 i}=\operatorname{arctg}\left(\operatorname{tg} \theta_{i}\right) ; i=\overline{1,2}$.

Ax1.4.3. We calculate the distance from the location of the barrel's position to the side of the tank.

Ax1.5. Condition (choice of position placement). If the position can be placed, then further. If not, then go to Ax1.2.

Ax1.6. Refined calculation (determination of the angle of inclination of the axis of the fire barrel to the horizon $\left(\theta_{0}\right)$ so that the trajectory of the water jet $y_{1}=x_{1} \cdot \operatorname{tg} \theta_{0}+\frac{x_{1} g}{\alpha \sqrt{2 g H}} \cdot \sqrt{1+\operatorname{tg} \theta_{0}^{2}}+\frac{g}{\alpha^{2}} \cdot \ln \left(1-\frac{\alpha x_{1}}{\sqrt{2 g H}} \cdot \sqrt{1+\operatorname{tg} \theta_{0}^{2}}\right)$ passes through some point $\left(x_{1}, y_{1}\right)$.

Ax1.6.1. We calculate according to Newton's scheme, with the initial approximations $\left(\xi_{0}\right)$ determined at step Ax1.4.1:

$$
\begin{aligned}
& f\left(\operatorname{tg} \theta_{0 n}\right)=x_{1} \cdot \operatorname{tg} \theta_{0 n}+\frac{x_{1} g}{\alpha v_{0}} \cdot \sqrt{1+\operatorname{tg} \theta_{0 n}^{2}}+\frac{g}{\alpha^{2}} \cdot \ln \left(1-\frac{\alpha x_{1}}{v_{0}} \cdot \sqrt{1+\operatorname{tg} \theta_{0}^{2}}\right)-y_{1} ; \\
& f^{\prime}\left(\operatorname{tg} \theta_{0 n}\right)=x_{1}-\frac{x_{1}^{2} g}{v_{0}^{2}} \cdot \frac{\operatorname{tg} \theta_{0 n}}{1-\frac{\alpha x_{1}}{v_{0}} \cdot \sqrt{1+\operatorname{tg} \theta_{0 n}^{2}}} .
\end{aligned}
$$

By integrating: $\operatorname{tg} \theta_{0 n+1}=\operatorname{tg} \theta_{0 n}-\frac{f\left(\operatorname{tg} \theta_{0 n}\right)}{f^{\prime}\left(\operatorname{tg} \theta_{0 n}\right)}, n=1,2, \ldots$

for the first initial approximation $\left(\operatorname{tg} \theta_{0}\right.$, determined at step Ax1.4.1), we obtain the valuestg $\theta_{01}, \operatorname{tg} \theta_{02}, \operatorname{tg} \theta_{03}$; for the second initial approximation $\left(\operatorname{tg} \theta_{0}\right.$, determined at step Ax1.4.1), we obtain the values $\operatorname{tg} \theta_{01}, \operatorname{tg} \theta_{02}, \operatorname{tg} \theta_{03}$, $\operatorname{tg} \theta_{04}, \operatorname{tg} \theta_{05}, \operatorname{tg} \theta_{06}, \operatorname{tg} \theta_{07}$.

Ax1.6.2. We calculate two angles of inclination of the axis of the fire barrel to the horizon (step Ax1.4.2.).

Ax1.6.3. We calculate the distance from the location of the position of the barrel to the side of the tank.

Ax1.7. Condition (choice of position placement). If the position can be placed, then further. If not, then go to Ax1.2.

Ax1.8. Calculation of the limiting horizontal displacements (determination of the interval of change in the angle of inclination of the axis of the fire barrel to the horizon $\left(\theta_{0}\right)$, at which the compact part of the jet will fall into the upper point of the tank side $y=y_{1}, x \in\left[x_{1} ; x_{2}\right]$ ).

Ax1.8.1. We calculate the values for Ax1.4.1., Ax1.4.2.

Ax1.8.2. We calculate the values:

for the lower extreme angle of inclination of the axis of the fire barrel to the horizon with an initial approximation, according to Ax1.6.1;

for the upper extreme angle of inclination of the axis of the fire barrel to the horizon with an initial approximation, according to Ax1.6.1.

Ax1.8.3. We calculate the distance from the location of the barrel's position to the side of the tank.

Ax1.9. Condition (choice of position placement). If the position can be placed, then move on. If not, then go to Ax1.2.

Ax1.10. Calculation of tank side cooling (determination of the interval of variation of the angle of inclination of the axis of the fire barrel to the horizon $\left(\theta_{0}\right)$, at which the compact part of the jet will move from top to bottom along a vertical line $x=x_{1}, y \in\left[y_{1} ; y_{2}\right]$.

Ax1.10.1. We calculate the extreme values of one of the intervals $\theta_{0} \in\left[\theta_{01} ; \theta_{02}\right]$ (hitting the segment from below) according to Ax1.4.1., Ax1.4.2.

Ax1.10.2. We calculate the values: for the lower extreme angle of inclination of the axis of the fire barrel to the horizon with an initial approximation, according to Ax1.6.1;

for the upper extreme angle of inclination of the axis of the fire barrel to the horizon with an initial approximation, according to Ax1.6.1.

Ax1.10.3. Condition (intersection of angle values). The intervals of change $\theta_{0}$ do not intersect with each other, then go to Ax1.8. If they intersect, then Ax1.10.1.

Ax1.11. Calculation of the limiting value (determination of the angle of inclination of the axis of the fire barrel to the horizon $\left(\theta_{0}\right)$, providing the maximum height $y_{l}$ of irrigation of the tank side). 
Ax1.11.1. Calculate the angle $\theta_{0}=\operatorname{arctg} \frac{2 H}{x_{1}}$.

Ax1.11.2. Calculate the maximum height $\max y_{1}=\frac{4 H^{2}-x_{1}^{2}}{4 H}$

Ax1.11.3. Calculating the values $\operatorname{tg} \theta_{0}=\frac{2 H}{x_{1}\left(1-\frac{2 H \alpha^{2}}{g}\right)} \cdot\left(1-\sqrt{1-\left(1-\frac{2 H \alpha^{2}}{g}\right) \cdot\left(1-\frac{\alpha^{2} x^{2}}{2 H g}\right)}\right)$.

Ax1.11.4. We calculate the value of the maximum height

$$
y_{1}=x_{1} \cdot \operatorname{tg} \theta_{0}+\frac{x_{1} g}{\alpha \sqrt{2 g H}} \cdot \sqrt{1+\operatorname{tg} \theta_{0}^{2}}+\frac{g}{\alpha^{2}} \cdot \ln \left(1-\frac{\alpha x_{1}}{\sqrt{2 g H}} \cdot \sqrt{1+\operatorname{tg} \theta_{0}^{2}}\right) \text {. }
$$

Ax1.12. Condition. If $x_{1}<2 H$, then further. If not (does not water the board), then go to Ax 1.8 .

Ax1.13. Output of solution results.

Ax1.14. Completion of the algorithm.

\section{Conclusion}

The semantic interpretation of the above algorithm is that the RTP step by step, based on the information received, can make decisions on the placement of the bunker's positions. At the same time, the RTP seeks to obtain a rational solution for the use of fire extinguishing resources, thereby launching a step-by-step process of coordinating the management of fire departments and emergency services. The convergence of the algorithm is satisfied by using finite arrays and parameters of the initial data. The time for entering values is in the range of 34 minutes, without a template. Calculation time - $5-10 \mathrm{sec}$. The calculations were carried out on an ASUS computer, i3-2350M CPU @ 2.30GHz 2.30GHz - RAM 4.00 GB.

Using this algorithm, an analysis was carried out of possible locations of bunker's positions in the tank farms of the Dung Quat and Ngi Son refineries for extinguishing and cooling the tanks during their combustion. The limiting values of the heads and angles of fire monitors for the option of extinguishing and cooling, located not on lifts indicate that no more than $30 \%$ of the territory (tank farms) can be used for their placement.

\section{References}

1. Volkov, O. M. Fire safety of tanks with oil products. / O.M. Volkov. [Text] - SPb: From the Polytechnic. University, 2010. $398 \mathrm{p}$.

2. Shertsov S.A., Kargashilov D.V., Potekha S.V., Bykov I.A. Estimation of the fire hazard of "big breaths" of ground tanks for storing petroleum products by numerical methods [Text] // Pozharovzryvobezopasnost. - 2017. - T. 26, №. 1. - P. 4351. DOI: 10.18322 / PVB.2017.26.01.43-51.

3. Kluban V.S., Panasevich L.T. Safe pumping of oil and fuel oil from burning vertical steel tanks [Text] // Fires and emergencies: prevention, elimination. - 2018. - №. 3. - P. 44-50. DOI 10.25257/ FE.2018.3.44-50.

4. Shvyrkov S.A., Goryachev S.A., Sorokoumov V.P., Batmanov S.V., Bopobiev V.V. Statistics of quasi-instantaneous destruction of storage tanks for oil and oil products [Text] // Pozharovzryvobezopasnost. - 2007. - T. 16, №. 6. - P. 48-52.

5. Shvyrkov, S.A. Fire risk at quasi-instantaneous destruction of an oil reservoir [Text]: monograph. - M: Academy of State Fire Service EMERCOM of Russia, 2015.

6. Danilov M.M., Denisov A.N., Oparin I.D. An approach to the formation of management decisions for fire extinguishing in a tank farm [Electronic resource] // Internet journal "Technosphere Safety Technologies" (http://academygps.ucozru/ttb). - №. 2 (54) 2014.

7. Denisov A.N., Nguyen Minh Huong. Some aspects of the organization of extinguishing fires at oil refining facilities in the Socialist Republic of Vietnam [Electronic resource] // Internet journal "Technosphere Safety Technologies" (http://academygps.ucoz.ruttb). - №. 6(December) 2007.

8. Denisov A.N., Nguyen Minh Huong. On the calculation of the forces and means of fire departments at the initial stage of extinguishing fires at oil refining facilities [Electronic resource] // Internet journal "Technologies of Technosphere Safety" (http://academygps.ucoz.ru/tb). - №. 4(32) - August 2010.

9. Dang Tyng. Investigation of the fire and explosion hazard of a tank with an oil product heated by a fire [Text]: Author's abstract. diss. .... Cand. sciences. - M.: MIPB Ministry of Internal Affairs of the Russian Federation, 1982 - 20 p.

10. Report on the work of the fire department 1998 - 2008 [Text] - UPO MOB SRV. Hanoi, 2007 - 41 p.

11. Report №. 577 on the work of the fire service in 2000 [Text] - UPO MOB SRV. Hanoi, December 2000 - 19 $p$.

12. Report №. 807 on the work of the fire department in 2001 [Text] - UPO MOB SRV. Hanoi, December 2001 $-19 p$.

13. Report on the work of the fire department in 2002 [Text] - UPO MOB SRV. Hanoi, $2002-19$ p.

14. Report №. 838 on the work of fire brigade in 2003 [Text] - UPO MOB SRV. Hanoi, December 2003 - 24 p. 
15. Report №. 648 on the work of the fire department in 2004 [Text] - UPO MOB SRV. Hanoi, November 2004 $-20 \mathrm{p}$.

16. Report №. 1121 on the work of the fire department in 2005 [Text] - UPO MOB SRV. Hanoi, December 2005 - $22 p$.

17. Report on the work of the fire department in 2006 [Text] - UPO MOB SRV. Hanoi, December 2006 - 24 p.

18. Report on the work of the fire department in 2007 [Text] - UPO MOB SRV. Hanoi, 2007 - 29 p.

19. Report №. 1107 on the work of the fire department in 2008 [Text] - UPO MOB SRV. Hanoi, December 2008 - $36 \mathrm{p}$.

20. Report on the work of the fire department in 2009 [Text] - UPO MOB SRV. Hanoi, $2009-12 \mathrm{p}$.

21. Report on the work of the fire department in 2010 [Text] - UPO MOB SRV. Hanoi, December $2010-19$ p.

22. Report on the work of the fire department in 2011 [Text] - UPO MOB SRV. Hanoi, November 2011 - 21 p.

23. Report №. 1889 on the work of fire protection in 2012 [Text] - UPO MOB SRV. Hanoi, November 2012 $21 \mathrm{p}$.

24. Report №. 2473 on the work of the fire department in 2013 [Text] - UPO MOB SRV. Hanoi, November 2013 - $28 p$.

25. Report №. 3386 on the work of the fire department in 2014 [Text] - UPO MOB SRV. Hanoi, November 2014 - $30 \mathrm{p}$.

26. Report №. 5568 on the work of the fire department in 2015 [Text] - UPO MOB SRV. Hanoi, November $2015-26 p$.

27. Report №. 4067 on the work of the fire department in 2016 [Text] - UPO MOB SRV. Hanoi, November $2016-30 p$.

28. Report on the work of the fire department in 2017 [Text] - UPO MOB SRV. Hanoi, November 2017 - 19 p.

29. Report on the work of the fire department in 2018 [Text] - UPO MOB SRV. Hanoi, November 2018 - 20 s. 